\title{
Entre a Transmissão e a Transferência: implicações éticas, pedagógicas e psicanalíticas da relação mestre-aprendiz no processo de ensino $e$ aprendizagem de línguas estrangeiras
}

[Between transmission and transference: ethic, educacional and psychoanalytical developments in the relationship master-apprentice in the process of foreign language teaching and learning] http://dx.doi.org/10.1590/1982-88371681835

\section{Érica S. Wels ${ }^{1}$}

\begin{abstract}
The current article was entailed by an understanding that teaching and learning processes (in the case in point, the teaching of German as a foreign language), as well as the development of specific classroom procedures, are influenced by both objective factors (methods, approaches, measurable tests and exercises) and subjective ones. Unlike Didactics, which emphasizes an objective perspective, it is believed here that elements such as personal interferences, and in particular those related to the figure of the master, heavily influence learning, at times stirring learners' feelings and even blocking apprentices altogether. Such aspects might be analyzed under the light of the Freudian concept of Transference, originally born in the psychoanalytic clinic. Another relevant psychoanalytical concept is sublimation, a productive and socially acceptable destination for psychological drives. Thus, teaching and learning are viewed as essentially sublimatory activities, and must, according to the view developed along this article, be stimulated by the master, with efforts channeled into the establishment of an awareness-raising and critical learning process, appropriate for the educational challenges of the twenty-first century. Whilst "psychoanalyzing" and deconstructing the pedagogical process, this article is grounded on a view of the classroom as a dialogic environment, wherein masters learn; and where learning is constructed through language and confrontation of otherness.
\end{abstract}

Keywords: Psychoanalysis, Teaching, Subjectivity, Alterity, German.

Resumo: O presente artigo parte da compreensão de que os processos de ensino-aprendizagem (no exemplo em questão, o ensino de Alemão como Língua Estrangeira), bem como o andamento de uma aula, são guiados tanto por fatores objetivos (métodos, abordagens, exercícios e testes passíveis de mensuração), quanto por subjetivos. Ao contrário da Didática, que privilegia um viés objetivo, fatos como interferências pessoais, sobretudo voltadas à figura do mestre, influenciam determinantemente a aprendizagem, a ponto de gerar bloqueios e mobilizar os sentimentos dos aprendizes. Tais aspectos podem ser explicados pelo conceito Freudiano de Transferência, nascido na clínica psicanalítica. Outro conceito psicanalítico relevante é a Sublimação, um dos destinos produtivos e socialmente aceitos da Pulsão. Dessa forma, o ensino e a aprendizagem configuram-se como atividades sublimatórias por excelência e que, por isso, de acordo com a visão desenvolvida nesse artigo, devem ser estimuladas pelo mestre, objetivando uma aprendizagem mais consciente e crítica, em sintonia com

\footnotetext{
${ }^{1}$ Universidade Federal do Rio de Janeiro (UFRJ), Faculdade de Letras, Departamento de Letras AngloGermânicas, Av. Horácio Macedo, 2151, 21941-917, Cidade Universitária, Rio de Janeiro/RJ, Brasil. Email: schludew@gmail.com
}

Pandaemonium, São Paulo, v. 18, n. 25, Jun. /2015, p. 168-183 
Wels, E. S. - Entre transmissão e transferência

os desafios educativos do século XXI. Além de "psicanalisar" e desconstruir o processo pedagógico, o artigo situa-se na concepção de uma sala de aula dialógica, com mestres que aprendem e que se constituem a partir da linguagem e do confronto com a alteridade.

Palavras-chave: Psicanálise; Ensino; Subjetividade; Alteridade; Alemão.

Zusammenfassung: Der vorliegende Artikel entspricht dem Verständnis, dass der Lehr- und Lernprozess (im behandelten Beispiel das Unterrichten von Deutsch als Fremdsprache), sowie der Fortschritt beim Unterrichten, durch objektive Faktoren (Methoden, Ansätze, Übungen und Aufgaben als Gegenstand der Einschätzung) als auch durch subjektive Faktoren gelenkt wird. Im Gegensatz zur Didaktik, bei der objektive Faktoren eine Rolle spielen, beeinflussen persönliche Interferenzen entscheidend das Lernen, vor allem solche, die auf die Figur des Lehrenden als Ausgangspunkt von möglichen Blockaden und Gefühlsmobilisationen des Erlernens bezogen sind. Diese Aspekte können mit dem Freudschen Begriff der Übertragung erklärt werden, der aus der klinischen Psychoanalyse übernommen worden ist. Ein weiteres relevantes psychoanalytisches Konzept ist die Sublimierung, als produktives und gesellschaftlich akzeptiertes Ziel des Triebes. Lehren und Lernen sind schlechthin sublimierende Aktivitäten, und, in Übereinstimmung mit der Vision dieses Artikels, sollten diese die Lehrenden mit der Zielstellung des bewussten und kritischen Lernens in Übereinstimmung mit den Bildungsanforderungen des 21. Jahrhunderts stimulieren. Neben einer ,psychologischen Betrachtung“ und der Dekonstruktion des pädagogischen Prozesses (als Lektüre und Analyseverfahren), fordert der Artikel eine dialoggesteuerte Unterrichtskonzeption von den Lehrenden, die ausgehend von der Sprache sich dieser Konzeption annehmen und in der Auseinandersetzung diese Alterität umsetzen.

Stichwörter: Psychoanalyse, Lehren, Subjektivität, Alterität, Deutsch.

Dedico esse artigo aos meus queridos mestres, aqueles que me ensinaram até mesmo o que desconheciam.

Não tenho dúvida do insucesso do cientista a quem falte a capacidade de adivinhar, o sentido da desconfiança, a abertura à dúvida, a inquietação de quem não se acha demasiado certo das certezas. Tenho pena e, às vezes, medo, do cientista demasiado seguro da segurança, senhor da verdade [...]. (FREIRE 2002)

\section{Introdução}

Por mais que a Ciência e o discurso científico se esforcem para lançar luzes sobre a complexidade de fatores que se desenrolam ao longo do processo de ensino-aprendizagem, permanecem ainda mais obscuras as razões subjetivas inerentes ao que se dá em sala de aula.

Em outras palavras, a Pedagogia e, mais ainda, a Didática, com seu estudo de métodos e abordagens (STORCH 2009; HunEKe / STEINIG 2010; Roche 2008), procuram elucidar objetivamente aquele processo que é, só em parte, objetivo, sendo, frequentemente, alvo de 
Wels, E. S. - Entre transmissão e transferência

dissabores, malentendidos e sentimentos ambivalentes que ligam mestres e aprendizes. Tal aspecto é reforçado pelas idéias de LÜHMANN (2006: 98), no artigo "Schule der Übertragung", no qual o autor questiona o suposto controle racional do andamento de uma aula: "Unterricht ist kein planungsrationales Geschehen, sein Gelingen hängt nur zu einem kleinen Teil von der Instruktionstechnik und zu einem großen von Faktoren ab, die in der Persönlichkeit der Lehrer und Schüler liegen ${ }^{2}$."

Não se trata aqui de instituir, no campo acadêmico, o critério do subjetivo como unicamente válido, em detrimento do objetivo. Por outro lado, observa-se, na prática docente e em estudos ligados aos processos de ensino e aprendizagem, um esgotamento no âmbito desses discursos, destinados, a exemplo da Medicina Tradicional, a tratar o sintoma, e não a causa dos males. Logo, como é de se esperar, a "doença" se manifesta em outro órgão e os resultados, em termos pedagógicos (no sentido de uma formação ética e humanística do indivíduo) são desiguais e insatisfatórios. Além disso, sente-se o mestre desmotivado, incapaz de ensinar para determinados alunos, ou sempre voltado a uma minoria, a qual faz melhor uso dos ensinamentos, por meio de estratégias de aprendizagem acumuladas durante a vida, e dos processos cognitivos inatos de assimilação dos saberes.

Para STOLZMANN e RicKes (1999), muito se espera do estudante quando este ingressa na escola; deseja-se sucesso absoluto na aprendizagem, pois se afirma que este somente tem por obrigação os estudos, ao contrário dos pais, sobrecarregados com o trabalho e as necessidades imperiosas da vida adulta moderna. Porém, “[...] mas que lugar melhor o sintoma teria para se alojar e implicar o outro, senão ali, no único lugar em que se espera um sucesso?” (STOLZMANN / RicKes 1999: 40). O que se deseja salientar aqui é que a visão de qualquer professor é um amálgama de experiências / vivências em contextos variados de ensino, lidando com as queixas e as alegrias dos alunos. Dito de outra forma, talvez soe muito pedagógico falar na dicotomia "fracasso" versus "sucesso"; parte-se da concepção de que qualquer professor, esteja no âmbito acadêmico ou não, conheça o fracasso, quando não consegue ensinar algo ou tenta, sem sucesso, se aproximar daquele aluno; quando observa, conversa, para, por fim, "perder" o jogo. Portanto, não se trata de instituir o "sucesso" ou o "fracasso" como as duas categorias possíveis para a transmissão de conhecimento, mas sim de entrar em franco diálogo com aqueles que ensinam; para, ao contrário, incluir o possível "fracasso" como categoria das mais humanas e previsíveis, até no contexto acadêmico, onde normalmente se espera encontrar alunos já minimamente "formados" e motivados:

\footnotetext{
2 "A aula não é nenhum acontecimento racionalmente planejado, seu êxito depende não somente de uma parte técnica de instruções, mas também, em grande parte, de fatores que residem na personalidade do professor e do aluno." [tradução nossa]
}

Pandaemonium, São Paulo, v. 18, n. 25, Jun. /2015, p. 168-183 
[...] Que há algo da instituição escola aí implicado, não há a menor dúvida. Mas, também não se resolve mudar a fachada ${ }^{3}$, como se diz, ou se inventar metodologias milagrosas, se não se buscar entender as fraturas que estão implicadas no processo de aprendizagem. O caminho que tal busca percorre está balizado pela concepção de sujeito que se tem e deseja, concepção esta que se comporta como a bússola a apontar para onde fica o norte. O que, nesses casos, contrariando a Geografia, pode variar dependendo da ética que está sustentando o olhar. (STOLZMANN / RICKES 1999: 41)

Esse artigo bebe nas fontes da Psicanálise, mas não a vê somente como clínica, mas sim como discurso e ética possível; nesse sentido, nos apropriamos de alguns de seus conceitos, a fim de elucidar um pouco do jogo de poder e de sentimentos ambíguos que unem mestre-aprendiz.

Outra contribuição da Psicanálise aponta para a inexistência da relação professoraluno. Seguindo o conhecido aforisma lacaniano de que a relação sexual não existe, pois não há equação exata entre o sujeto e o objeto de sua satisfação, a relação professor-aluno, aqui chamada mestre-aprendiz, não passa de uma relação abstrata. Como afirma Voltolini (2007), essa relação “[...] ideal, tal como prescrita nas teorias pedagógicas atuais, é a condição de possibilidade para que existam relações estas sempre marcadas pela incompletude e pelo impossível" (Voltolini 2007: 122).

\section{Psicanálise e Educação}

Com o objetivo de realizar um Pós-Doutorado que me situasse na interseção dos saberes acima mencionados, iniciei um levantamento de programas de Pós-Graduação de várias instituições brasileiras, e me deparei com a aplicação clínica da Psicanálise (em sua maioria, e voltada sobretudo a graduados em Psicologia) ${ }^{4}$, com a contribuição significativa de Jacques Lacan (teorias do discurso, da linguagem e da tradutologia), ou a aplicação dos conceitos e textos de Sigmund Freud nas áreas de Estudos Literários e Artes. Percebi, assim, uma lacuna no diálogo entre Psicanálise e Pedagogia, notadamente entre professores e educadores e, mais ainda, no cerne dos discursos que refletem a sala de aula de línguas estrangeiras, uma das motivações dos pesquisadores de Linguística Aplicada, por exemplo.

\footnotetext{
${ }^{3}$ Grifo destacado pelas autoras do artigo.

${ }^{4}$ É importante mencionar que há diversos trabalhos na área da Psicologia da Educação, relacionando Psicanálise e Educação, mas produzidos por pesquisadores da Psicologia. Refiro-me, mais especificamente, a professores ou educadores estudando Psicanálise.
} 
Wels, E. S. - Entre transmissão e transferência

De qualquer forma, segundo ASSIS (2003), realizar um "casamento" entre psicanálise e educação é tão desejável, quanto difícil. No entanto, a autora afirma que a psicanálise em muito pode contribuir para a educação, vislumbrando um futuro promissor para esse encontro.

Leny Magalhães MRECH (2008), através de trabalhos de orientação lacaniana, dentro desta temática, também sugere que a psicanálise possa oferecer novas guias, novos parâmetros, através dos quais é possível repensar o fazer e as relações pedagógicas, que se encontram imersas numa nova configuração de mundo, de saber, de ensino.

Uma das críticas que normalmente é dirigida a tais abordagens refere-se às dificuldades de aplicabilidade dos preceitos psicanalíticos no campo do ensino, além de pontos de distanciamento entre os discursos pedagógico e psicanalítico, alguns dos quais mencionaremos aqui.

Quando se discorre sobre Educação, a tônica bastante presente é o modelo de educação ideal, universal, coletiva; tal aspecto acaba por excluir a singularidade e, consequentemente, os caminhos de construção do saber pelo próprio sujeito, ao invés de simplesmente sua reprodução. Como considerar a singularidade num espaço pensado para o coletivo?

Tendo em vista o fato de que a ética da Psicanálise é a ética da diferença, esta se ocupa, portanto, do singular que cada sujeito traz com seu sintoma e sua modalidade de gozo. Ora, conviver com a diferença é um dos maiores desafios do século XXI, e é na Educação que devemos encontrar um discurso de tolerância e respeito ao Outro, além do estímulo de com este Outro aprender. Mrech (2008), ao resumir alguns dos conceitos mais importantes do pensamento lacaniano, situa no Seminário 11 a primeira fala de Lacan acerca das concepções do inconsciente freudiano: o inconsciente freudiano seria calcado no Outro, na transferência e no retorno do recalcado; Lacan aproxima o inconsciente da Linguística ao revelar que o inconsciente é estruturado como uma linguagem. O inconsciente lacaniano é pulsante, em permanente movimento. Ainda segundo a explanação de Mrech, o último ensino de Lacan, que ocorre após o Seminário 20, traz a radicalização de todos os conceitos, levando à renúncia de uma leitura do Outro pautada no universal, na cultura e na linguagem, privilegiando aquilo que é da ordem do Um e do singular de cada sujeito. No Seminário 20, revela que a realidade é abordada mediante os aparelhos de gozo e explica que esses aparelhos são da ordem da linguagem. A partir daí, o teórico não acredita mais que a linguagem seja o eixo central de seu pensamento e fala de uma mudança da linguagem para a linguisteria. Em seus escritos, Lacan oferece diversos elementos que contribuem para uma virada na visão do sujeito, numa sociedade que privilegia exatamente o gozar, não mais pautada somente pelo simbólico. 
Wels, E. S. - Entre transmissão e transferência

Contudo, não é nosso objetivo oferecer uma leitura detalhada dos preceitos lacanianos, que fogem ao nosso corpus de pesquisa e aos limites do presente trabalho. É válido afirmar que, através desses breves aspectos do pensamento lacaniano, resumidos por Mrech, a psicanálise é convidada a dialogar com a cultura, suas instituições e suas novas configurações.

Em consonância com o que foi exposto acima, Paulo FrEIRE (1996), em sua Pedagogia da Autonomia, chama a atenção para o par formador-aluno, estabelecendo a complexidade como possível chave de entendimento nessa troca:

Se, na experiência de minha formação, que deve ser permanente, começo por aceitar que o formador é o sujeito em relação a quem me considero o objeto, que ele é o sujeito que me forma e eu, o objeto por ele formado, me considero como um paciente que recebe os conhecimentos conteúdos-acumulados pelo sujeito que sabe e que são a mim transferidos. (FREIRE 2003: 22)

A conclusão dessa passagem, na qual sujeito - objeto se confundem, pois todos são sujeitos que aprendem, leva a um dos mais conhecidos aforismos freireanos: "Quem ensina aprende ao ensinar e quem aprende ensina ao aprender. Quem ensina ensina alguma coisa a alguém." (FREIRE 2003: 23)

\section{A Transferência}

Subjacentes aos processos objetivos que ocorrem na sala de aula de línguas estrangeiras, como os inúmeros recursos didáticos que facilitam a transmissão de conhecimento (também de natureza objetiva, ou seja, passíveis de mensuração e teste), ocorrem processos de natureza subjetiva.

Trata-se da resistência a alguns mestres, por parte dos aprendizes, dos bloqueios que estes apresentam ao lidarem com este ou aquele professor. Vale ressaltar que tais aspectos, em se tratando de uma língua estrangeira complexa, como o Alemão, possuem um peso relevante na conjugação de fatores que contribuem para uma sala de aula de boa atmosfera e propícia ao aprendizado. Destaca-se a construção de um ambiente diálogico, de troca e interação, na qual o mestre se mistura ao processo, e não permanece acima dele, como algumas práticas pedagógicas o pintam. Novamente, é uma contribuição freireana que resume a complexidade desse processo: "É que o trabalho do professor é o trabalho do professor com os alunos e não do professor consigo mesmo." (FREIRE 2003: 64). 
Nessa mesma direção, Lühmann destaca o perigo na crença de verdades absolutas, passada por trás de instruções requintadas, técnicas e abordagens, trazendo, em seu lugar, algo inapreensível ("Etwas nicht faßbares ist im Spiel") para o centro das possibilidades que procuram explicar quando "uma aula dá certo" ou "dá errado":

Erfolg oder Misserfolg hängen offensichtlich nur zum Teil davon ab, ob der Unterricht 'lehrerzentriert', 'fragend-entwickelnd' in Gruppenarbeit, als entdeckendes Lernen oder gar nicht organisiert ist. Auch Verhaltensweisen des Lehrers, die noch vor aller Methode wichtig und wirksam sind - wie zum Beispiel Klarheit der Ziele, sicheres Auftreten und regelmäßiges Wiederholen -, garantieren keinen Erfolg. Etwas nicht faßbares ist im Spiel [...]. ${ }^{5}$ (LÜHMANN 2006: 98-99)

Além disso, seria ensinar algo místico, transcendental, ou algo próximo do concreto, facilmente transmissível, como uma "receita de bolo"? (STOLZMANN / RICKES 1999: 41). Será que basta a intenção daquele que ensina, para alcançar aquele que aprende? E se o aprendiz não apresenta disposição para conhecer o que se lhe quer ensinar? Aqui reside um dos maiores problemas dos discursos acerca do ensinar, seja qualquer um o objeto de ensino: como se houvesse uma equação composta por dois polos, e, ao acionar o lado que ensina, o lado que aprende automaticamente recepcionasse os conteúdos. Quem ensina, percebe que o processo caminha por outras vias, menos óbvias, de uma complexidade que vai além da vontade pura e consciente de ensinar, e dos aparatos que cercam esses esforços.

Um dos conceitos que melhor sintetiza tais fenômenos é a Transferência (Übertragung), termo Freudiano de ampla repercussão e, até hoje, um dos pilares do trabalho na clínica psicanalítica.

Glauben Sie übrigens nicht, dass das Phänomen der Übertragung [...] durch die psychoanalytische Beeinflussung geschaffen wird. Die Übertragung stellt sich in allen menschlichen Beziehungen ebenso wie im Verhältnis des Kranken zum Arzte spontan her, sie ist überall der eigentliche Träger der therapeutischen Beeinflussung, und sie wirkt um so stärker, je weniger man ihr Vorhandensein ahnt. ${ }^{6}$ (FREUD 1909: 63)

Apesar de a transferência ser a base da clínica psicanalítica, ela se manifesta em grande parte das relações humanas, sendo comparável, no senso comum, àquele sentimento de antipatia ou aversão gratuita que experimentamos, ao nos relacionarmos com outras pessoas. “[...] Todas

\footnotetext{
5 "O sucesso ou o fracasso dependem evidentemente somente em parte, se a aula for 'centrada no professor', 'desenvolvida a partir de questionamentos' em trabalho de grupos, como uma aprendizagem a partir da descoberta, ou se nem for organizada. Também o comportamento do professor, que é mais importante e eficaz que qualquer método - assim como, por exemplo, a clareza dos objetivos, postura segura e revisão regular -, não garante o sucesso. Algo que não é apreensível está em jogo.” [tradução nossa]

6 "Não pensem, além disso, que o fenômeno da Transferência [...] seja produzido pela influência da psicanálise. A Transferência surge espontanemente em todas as relações humanas e de igual modo nas que o doente entretém com o médico; é ela, em geral, o verdadeiro veículo da ação terapêutica, agindo tanto mais fortemente quanto menos se pensa em sua existência." (Tradução da Editora Imago)
}

Pandaemonium, São Paulo, v. 18, n. 25, Jun. /2015, p. 168-183 
Wels, E. S. - Entre transmissão e transferência

as nossas relações pessoais são permeadas por emanações de energias psíquicas desconhecidas oriundas de um território obscuro e inatingível." (CUNHA 2012: 4). Em outras palavras, a Psicanálise ensina que transferimos sentimentos diversos, a partir de nossas vivências anteriores, as quais deixaram marcas psíquicas inconscientes. Após essas breves definições, pode-se entender o porquê da Educação ser um campo marcado fortemente pelo fenômeno transferencial.

Antes de prosseguirmos, vale a pena comentarmos um pouco do percurso do conceito da Transferência. O termo não é exclusivo do vocabulário psicanalítico, característica, a propósito, que se presta a muitos outros conceitos freudianos. Utilizada em inúmeros campos, a transferência implica uma ideia de deslocamento, de transporte, de substituição de um lugar por outro, sem que esta operação afete a integridade do objeto (ROUDINESCO / PLON 1998: 767). Todas as correntes do Freudismo consideram a transferência essencial para o processo psicanalítico, porém, conforme as escolas, há divergências quanto ao seu manejo pelo analista, ao seu lugar no tratamento, entre outros aspectos.

Historicamente, ela passa a ser utilizada e reconhecida por Freud após o abandono da hipnose e da catarse, permitindo a inovação, para as psicoterapias da época, de usá-la como instrumento de cura no processo de tratamento. A princípio (Estudos sobre a histeria, A Interpretação dos sonhos), Freud localiza a transferência como "um deslocamento do investimento no nível das representações psíquicas, mais do que um componente da relação terapêutica" (ROUDINESCO / PLON 1998: 767). Por fim, pode-se dizer que a transferência surge a partir dos relatos de Anna O. (Bertha Pappenheim), em tratamento com Josef Breuer e, na obra de Freud, a partir da análise de Dora (Ida Bauer), em 1905. Esta experiência apresenta-se como negativa, pois Freud, como psicanalista, se recusa a ser objeto do arroubo amoroso de sua paciente, opondo-lhe resistência, que, em contrapartida, produz uma transferência negativa por parte de Dora. Tal posicionamento é mais tarde chamado por Freud de Contratransferência. Em 1912, em seu primeiro texto voltado exclusivamente para o tema, intitulado "A dinâmica da transferência", Freud começa a perceber que os sentimentos inconscientes do paciente para com o analista são baseados em imagens parentais. Distingue a transferência positiva, feita de ternura e amor, da negativa, vetor de sentimentos hostis e negativos, além da mista, que reproduz sentimentos ambivalentes da criança em relação aos pais.

RoudinesCo e Plon (1998) destacam ainda o nome de Sandor FERENCZI, que, desde 1909, observa a transferência presente em todas as relações humanas: entre professor e aluno, 
Wels, E. S. - Entre transmissão e transferência

médico e paciente. No entanto, Ferenczi salienta que na análise o paciente coloca inconscientemente o terapeuta numa posição parental.

Através de uma de suas frases mais citadas, Freud nos ensina que a educação, juntamente com o governo e a Psicanálise, estaria entre as três profissões impossíveis, situadas num contexto de algo que sempre escapa, movido por amores e dissabores, e diferentemente de outros saberes, a mercê do desejo: "Es hat doch beinahe den Anschein, als wäre das Analysieren der dritte jener 'unmöglichen' Berufe, in denen man des ungenügenden Erfolgs von vornherein sicher sein kann. Die beiden anderen, weit länger bekannten, sind das Erziehen und das Regieren. "7 (FREUD 1937: 59)

A Psicanálise pode ser pensada, portanto, como uma ética possível, muito além da moldura de uma metodologia ou dos alicerces aparentente seguros de um método. É a área que institui o sujeito desejante como paradigma, e enxerga o processo de aprendizagem como feito de "saltos e pulos", longe de um acúmulo linear e progressivo de conhecimentos. Há algo de filosófico e socrático aí, na figura do parteiro de ideias, o mestre menos intervencionista e que vê no ensinar e no aprender grandes experiências na direção de instruir um sujeito na busca de seu próprio caminho e na construção de seu próprio conhecimento.

Ainda sobre a transferência e retomando Lacan, argumenta WILLEMART (1996: 207):

Quantas vezes ouvimos alunos que, ruins em matemática com tal professor, acordam com outro e passam a entender. A formação aos pulos e aos saltos da qual fala Lacan acontece nesse despertar da transferência, momento após o qual tudo parece fácil de entender e memorizar. Mas não podemos exigir esse ideal de todos [...].

Nesse sentido, Willemart chama a atenção para o fato de que a transmissão mesma nos escapa e, assim como o inconsciente, é constituída pelo dinamismo e pela atualização. O que vale destacar nesse fragmento, ancorados por Lacan é a falha, a falta, o fracasso, elementos que, às vezes aparecem nos discursos de professores como algo surpreendente e inexplicável, e, principalmente, muito distantes da proposta didático-pedagógica consistente passada em sala de aula.

Outro dia, uma ex-aluna que fez uma disciplina de pós em 1982 me disse: "Nunca esquecerei o que o senhor falou neste ano". Ela não foi muito explícita, mas podemos afirmar que não é para se preocupar muito com o resultado efetivo de nosso ensino. Não são certos métodos de avaliação tão na moda atualmente que vão averiguar um ensino ruim ou mau. Estas avaliações dos professores pelos alunos refletem apenas um ponto de vista imaginário e do momento, que gira em torno do gostar ou não gostar do professor; [...] Resumindo, a "pedagogia" entre aspas proposta pela psicanálise gira ao redor de saltos e pulos, incentiva o fracasso, o inacabado e a

\footnotetext{
7 'Quase parece como se a análise fosse a terceira daquelas profissões 'impossíveis' quanto às quais de antemão se pode estar seguro de chegar a resultados insatisfatórios. As outras duas, conhecidas há muito mais tempo, são a educação e o governo.” (Tradução da Editora Imago)
} 
Wels, E. S. - Entre transmissão e transferência

repetição obstinada, consiste em interpretar as informações para abrir os ouvintes a outras redes simbólicas ...]. (WILLEMART 1996: 209).

\section{Mestre e aprendiz na dinâmica da transferência}

A relação professor-aluno é, à primeira vista, das mais simples. Para muitos, a relação pedagógica é definida a partir da escolha de um bom método de ensino, uma distribuição adequada do conteúdo pelo tempo disponível e um certo conhecimento das competências intelectuais e dos perfis dos aprendizes. Contudo, quem ensina, seja como professor "formado" ou em formação, já é capaz de perceber que algo escapa a esse arranjo. E é capaz de escapar por entre os dedos, entre o giz e a lousa, a toda aula. Os ensinamentos psicanalíticos dirigem nossa atenção para o vasto mundo subjetivo que emerge de mestres e aprendizes, cada qual sofrendo constantemente a pressão de seus desejos, alguns dos quais reprimidos. "O professor que conhece a Psicanálise sabe que o conhecimento está sempre permeado pelo desejo.” (CUNHA 2012: 4)

[...] O professor que aceita o paradigma psicanalítico está sempre interessado em ir além de ministrar uma boa aula - no sentido técnico da expressão. Seu olhar volta-se constantemente para os motivos desconhecidos que o levam a estar ali, as possíveis razões que o motivam a relacionar-se com os alunos desta ou daquela maneira. Ele é um profissional que tende a valorizar menos a manutenção do bom comportamento de seus educandos e mais a livre expressão das crianças e dos jovens que estão sob os seus cuidados. (CUNHA 2012: 4)

Conhecer o conceito da transferência, por parte dos mestres, é minimamente necessário a um melhor manejo das relações que se desenrolam em sala de aula, concebendo-a como palco de subjetividades em conflito e interação, e alvo de jogos de poder.

KUPFER (1986) sustenta, como condição do mestre, ser aquele que possibilita o acesso do aluno ao conhecimento. Há, portanto, um desejo de transmissão, de ensinar algo a alguém que está na posição de querer saber (o que não é pouco): "Pela via da transferência o aluno passará por ele - pelo professor -, usá-lo-á, por assim dizer, saindo dali com um saber do qual tomou posse e que constituirá a base e o fundamento para futuros saberes e conhecimentos." (KUPFER 1986: 100)

Vale ressaltar que a transferência implica uma suposição de saber, em que vai se fundar a autoridade do professor. É preciso, dessa forma, que este possa sustentar aquilo que o aprendiz lhe endereça. Só assim será possível ensinar. 
Wels, E. S. - Entre transmissão e transferência

Retornamos, assim, ao par subjetividade-alteridade, já que a transferência se manifesta obrigatoriamente de um sujeito para outro. $\mathrm{O}$ mestre, a exemplo da contribuição freudiana, pode ser presa da chamada Contratransferência, guardando sentimentos complexos e, às vezes, contraditórios, em relação aos seus aprendizes, mas igualmente determinantes na dinâmica da relação de ambos. "Wenn Menschen einander belehren, dann ist dies kein neutrales Verhältnis geschickter Manipulation wie vielleicht zwischen Handwerksmeister und Werkstück."8 (LÜHMANN 2006: 99).

Portanto, a transferência é dinâmica, passível de construções e desconstruções permanentes e essencial ao jogo de poder e de afeições, desejo e vontade, que se instaura em qualquer sala de aula. Freud, ao falar de mestres e aprendizes, a julga indispensável:

Wir warben um sie [unsere Lehrer] oder wandten uns von ihnen ab, imaginierten bei ihnen Sympathien oder Antipathien, die wahrscheinlich nicht bestanden, studierten ihre Charaktere und bildeten oder verbildeten an ihnen unsere eigenen. Sie riefen unsere stärksten Auflehnungen hervor und zwangen uns zur vollständigen Unterwerfung; wir spähten nach ihren kleinen Schwächen und waren stolz auf ihre großen Vorzüge, ihr Wissen und ihre Gerechtigkeit. Im Grunde liebten wir sie sehr [...]; ich weiß nicht, ob alle unsere Lehrer dies bemerkt haben. [...] Wir waren von vornherein gleich geneigt zur Liebe wie zum Hass, zur Kritik wie zur Verehrung gegen sie. [... $]^{9}$ (FREUD 1914: 256).

Outro aspecto relevante na relação que aqui se propõe é instituir o espaço da sala de aula como eminentemente dialógico, palco de interação, no qual convergem inúmeros discursos (BAKTHIN [1929] 1986). Conceber esse dialogismo como troca, e não como arma de poder (fortalecimento da hierarquia entre professor e aluno), contribui para uma aprendizagem mais democrática e em sintonia com as demandas sociais do século XXI. Trata-se da pluralidade dialógica e do direito à expressão, numa forma de saber construída, distante, assim do saber convencional, passível de medição e avaliação.

\section{Sublimação: breves aspectos}

Além do conhecimento do campo transferencial, salientamos outro termo presente em vários escritos de Sigmund Freud: a Sublimação.

\footnotetext{
8 "Quando os seres humanos ensinam uns aos outros, então o que se dá não é uma relação neutra de uma manipulação habilidosa, como talvez entre um artesão e a peça a ser trabalhada." [Tradução nossa]

9 "Nós os [nossos professores] cortejávamos ou lhes virávamos as costas; imaginávamos neles simpatias e antipatias que provavelmente não existiam; estudávamos seus caráteres e sobre estes formávamos ou deformávamos os nossos. Eles provocavam nossa mais enérgica oposição e forçavam-nos a uma submissão completa; bisbilhotávamos suas pequenas fraquezas e orgulhávamos-nos de sua excelência, seu conhecimento e sua justiça. No fundo, sentíamos grande afeição por eles, se nos davam algum fundamento para ela, embora não possa dizer quantos se davam conta disso.” (Tradução da Editora Imago)
}

Pandaemonium, São Paulo, v. 18, n. 25, Jun. /2015, p. 168-183 
Wels, E. S. - Entre transmissão e transferência

$\mathrm{Na}$ Alquimia, tal processo designava o processo de modificação radical que convertia o estado sólido em gasoso sem a mediação do estado líquido. No Alemão, Sublimierung, indica um movimento de ascensão ou elevação daquilo que se sustenta no ar. O escritor Johann Wolfgang von Goethe utiliza essa palavra, vinculando-a a uma necessidade de trabalho do espírito, onde sentimentos e acontecimentos precisariam ser "trabalhados, acomodados, sublimados."

Dentro da teoria psicanalítica, a pulsão pode ser recalcada, revertida em seu oposto, retornar em direção ao eu ou ser sublimada. Na sublimação, a pulsão mantém o seu teor sexual, porém sua finalidade passa a ser social.

O termo foi empregado por Sigmund Freud em 1905 (Três ensaios sobre a teoria da sexualidade) para designar o ato de impulsionar. Carga energética que se encontra na origem da atividade motora do organismo e do funcionamento psíquico inconsciente do homem. O conceito está estreitamente ligado aos conceitos de libido e de narcisismo. Em 1905, pulsão era essencialmente a pulsão sexual. Na edição de 1910 dos Três Ensaios, Freud define a pulsão como uma demarcação entre o psíquico e o somático: Pulsão é a representação psíquica de uma fonte endossomática de estimulações que fluem continuamente, em contraste com a estimulação produzida por excitações esporádicas e externas.

Freud diferencia pulsão sexual de instinto sexual. Para ele, a pulsão sexual não se reduz às atividades sexuais, mas é um impulso cuja energia é constituída pela libido. Diferencia a pulsão sexual das outras pulsões. A pulsão sexual é composta da satisfação genital e da função de procriação. (ROUDINESCO / PLON 1998)

No processo sublimatório, o eu possui um papel importante por se constituir como instância capaz de reter uma reserva de libido, adiando a satisfação e deslocando energia para fins considerados nobres. A sublimação se origina dentro dos impasses da satisfação pulsional direta, passa pelas exigências culturais coercitivas, até intercambiar um objetivo primeiro por um outro, valorizado do ponto de vista estético e moral: "A libido vem encontrar sua satisfação nos objetos [...], objetos socialmente valorizados, objetos aos quais o grupo pode dar sua aprovação, uma vez que são objetos de utilidade pública.” (FREUD 1905: 167)

Por que o conceito de "Sublimação" é igualmente importante, na pesquisa dos processos subjacentes ao ensinar / aprender? A arte é vista por Freud como uma satisfação substitutiva e psiquicamente eficaz, devido ao papel que a imaginação e a fantasia ocupam na vida anímica; de acordo como pensar Lacaniano, ela é um modo específico de organização em torno do vazio. Os três termos que Freud define para a "sublimação" são a arte, a religião e a ciência. 
Wels, E. S. - Entre transmissão e transferência

Logo, incluímos aprendizagem como "ciência", segundo os termos freudianos que promovem a sublimação. Vale destacar que a "sublimação" é um processo inconsciente, mas que, pode ser desencadeada através de uma fonte concreta e consciente. Em outras palavras, promover e estimular o saber são formas simples que o professor e a instituição de ensino possuem para promover a sublimação. Em termos psicanalíticos, a sublimação geraria sujeitos mais dispostos a aprender e capazes de viver melhor, lidando com os seus desejos. Afinal, os desejos contrários, a repetição e a resistência são velhos conhecidos dos professores.

\section{Transmissão e transferência}

Finalmente, relacionamos o conceito de transmissão (STOLZMANN / RICKESS 1999), oriundo da área da Pedagogia e em diálogo com a transferência acima descrita. Outros processos se dão no cenário do ensino; entre eles, a transmissão, que é definida como a capacidade, a disponibilidade do professor em transmitir conhecimento, transferindo saberes e fortalecendo seu papel em todo o processo. A qualidade da transmissão deve ser ressaltada, e é ela que faz daquele que ensina um mestre. Porém, já nos ensinam diversos teóricos da Educação, notadamente Paulo Freire $(2003,2011)$ que o saber pressupõe humildade, e, sobretudo, devese continuamente desejar aprender. Tal postura repudia qualquer pressão hierárquica, distanciando o mestre da mais importante fonte de aprendizagem do ensinar: o próprio aprendiz.

Há algo no processo de ensinar e aprender que escapa à tentativa de tirar alguém do "limbo da ignorância e passá-lo para o lado dos que conhecem" (STOLZMANN / RICKES 1999: 41). Esse algo talvez seja a afetividade, o amor transferencial, ou a vontade de transmitir, que gera a vontade de saber.

Esse posicionamento permite a consciência essencial de que cada aluno deve recriar o caminho da construção do conhecimento de forma original. Nesse sentido, a própria biografia de Freud é exemplar na promoção de uma vida marcada pelo desejo de saber, pela superação via processos sublimatórios, e pela consciência de que é necessário amar o seu mestre, para, enfim, tornar-se o mestre de si mesmo. A respeito de seus mais importantes mestres e antecessores, é o próprio Freud que reconhece: “[...] Breuer, Charcot e Chobrack, esses três homens tinham me transmitido um conhecimento que, rigorosamente falando, eles próprios não possuíam” (apud KUPFER 1989: 26). 
Wels, E. S. - Entre transmissão e transferência

Nesse sentido, a concepção de Freud sobre o ensino e a transmissão parte da ideia de que o professor transmite até o que não possui. É o que defende Ferreira:

Essa formulação nos permite pensar no ato de ensinar. Primeiro, que a constituição do saber por um aluno tem vicissitudes que aquele que ensina ignora. Depois, a de que a transmissão pode acontecer sem uma mediação do saber e na presença ausência, por assim dizer, daquele que ensina, no vazio que ele deixa, para que o desejo de saber se instaure no outro. Na possibilidade do aluno operar uma dessuposição de saber naquele que ensina (FERREIRA 2001: 144).

Em outras palavras, a posição e o(s) discurso(s) que o professor assume é o que vai determinar se seu ato pedagógico transmite o saber ou o desejo de saber no aluno. $\mathrm{O}$ desenrolar da relação se dá via transferência de sentido, ou seja, o aluno atribui ao professor um sentido especial (aquele capaz de despertar nele o desejo de saber). No entanto, o professor tende a se apoderar desse sentido especial e passa a ocupar uma posição de mestre sabe-tudo que tem nas mãos o saber sobre o desejo do aluno. Só que esse saber que o professor julga possuir sempre lhe escapará.

Segundo FERREIRA (2001), o professor é o objeto da transferência e entra, com seu ser, na economia libidinal do aluno. Isso pode possibilitar tanto que o sujeito produza um saber, quanto que se feche a essa experiência. Pode levar tanto a uma produção quanto a uma destituição dessa possibilidade, segundo o lugar que ocupa para o aluno e segundo também o tratamento que o professor venha a dar ao que desponta dessa e nessa relação.

A partir dessa perspectiva, o entendimento da relação professor-aluno e do ato pedagógico ganha novos contornos e podem passar a ser construídos a partir do inusitado, das incertezas, das incongruências, e não simplesmente referenciados pelos modelos préestabelecidos, antecipando e ditando os passos da relação e ato pedagógicos.

Assim, abordar a noção psicanalítica de transferência no terreno educacional nos permite entender melhor a relação professor-aluno, compreendendo que ela não é um processo que se dá à toa, mas que diz algo da realidade psíquica dos agentes envolvidos no processo educacional.

Minimamente, ao mostrar que muitos dos fenômenos da sala de aula são mais humanos, isto é, subjetivos, do que técnicos, o paradigma psicanalítico abre um campo frutífero de diálogo e reflexão para mestres e alunos, em busca de uma vivência que reconhece a alteridade. Estar com o outro, respeitá-lo e com ele (con)viver, reside aí um dos maiores desafios e delícias do ensinar. Solicita-se, então, menos preocupação com o método, e mais cuidado com o sujeito, razão principal de todo o processo. Ou seja, o que as ideias freudianas sugerem é uma ética, longe de ser uma doutrina, ou um catálogo de instruções. A 
Wels, E. S. - Entre transmissão e transferência

Psicanálise encaminha o professor para um reconhecimento das fragilidades do processo pedagógico, deslocando-o do centro de poder, minimizando-lhe a angústia e tornando-o uma pessoa menos obcecada com a imposição de seu ponto de vista, de sua moral, sua Verdade. Nessa perspectiva, ainda que utilizemos a expressão "mestre", não remetemos à acepção tradicional que essa palavra comporta, como autoridade suprema, de saber indiscutível e capaz de disciplinar e impôr a ordem, de fazer alunos obedecerem. Entre os fatores que contam na assimilação dos conteúdos escolares estão as disposições inconscientes favoráveis, quando se dá algo positivo, ou desfavoráveis, que convergem para o fracasso, isto é, mais para desejos que situam no campo de fenômenos interpessoais, transferenciais, diversos, do que às peculiaridades do método de ensino ou do material didático.

Nesse sentido, os autores que se ocupam desse campo de investigação, convergem para um ponto em comum: a importância da liberdade de pensar, de especular, de elaborar hipóteses, reformulá-las e, até mesmo, abandoná-las, dando sempre lugar ao novo. Souza (2003) lembra que a obra de Freud é marcada por esse movimento, e que sua genialidade estava em sua liberdade de pensar. Igualmente, a obra de Jacques Lacan, apresenta-se marcada por essa espontaneidade na relação com o saber.

Esperamos, com o texto exposto, ter fornecido pontos de reflexão, no sentido de "psicanalisar" e desconstruir a pedagogia da sala de aula, a fim de melhor entender os bloqueios e obstáculos na aprendizagem de línguas estrangeiras. Não é nosso objetivo curar as práticas da sala de aula, mas pelo menos deixá-las falar...

\section{Referências bibliográficas}

Assis, Maria Bernadete Amêndola Contart de, 'Psicanálise e educação: passado, presente, futuro, perspectivas', in OLIVEIRA, Maria Lúcia (org.). Educação e psicanálise: história, atualidade e perspectivas. São Paulo: Casa do Psicólogo, 2003.

BAKTHIN (1929), Marxismo e filosofia da linguagem. 3. ed. São Paulo: Hucitec, 1986.

CruXÊN, Orlando, A Sublimação. Psicanálise Passo a Passo 51. Rio de Janeiro: Jorge Zahar, 2004.

Cunha, Marcos Vinicius da. 'Freud: Psicanálise e Educação'. In: Psicologia da Educação, São Paulo, Unesp, $\quad 2012, \quad 1-21$. http://www.acervodigital.unesp.br/bitstream/123456789/140/3/01d08t01.pdf/ (04/08/2014).

GARCIA-RoZA, Luiz Alfredo, Freud e o Inconsciente. 14. ed. Rio de Janeiro: Jorge Zahar, 1997.

FÉDIDA, Pierre, Clínica Psicanalítica: Estudos. Trad. Claudia Berliner, Martha Prada e Silva e Regina Steffen. São Paulo: Editora Escuta, 1988.

FreIRE, Paulo, Pedagogia do Oprimido. 50. ed. r. e atual. Rio de Janeiro: Paz e Terra, 2011. , Pedagogia da Autonomia: saberes necessários à prática educativa. 27. ed. Rio de Janeiro: Paz e Terra, 2003 [1996].

FREUD, S. 'Três ensaios sobre sexualidade (1905)' in Obras psicológicas completas de Sigmund Freud. Edição standard brasileira. Rio de Janeiro: Imago, 1976. Vol. VII.

Pandaemonium, São Paulo, v. 18, n. 25, Jun. /2015, p. 168-183 
Wels, E. S. - Entre transmissão e transferência

'Cinco lições de psicanálise (1909)' in Obras psicológicas completas de Sigmund Freud. Edição standard brasileira. Rio de Janeiro: Imago, 1976. Vol. XI

'Leonardo da Vinci e uma lembrança da infância (1910)' in Obras psicológicas completas de Sigmund Freud. Edição standard brasileira. Rio de Janeiro: Imago, 1976. Vol. XI

'A Dinâmica da Transferência (1912)' in Obras psicológicas completas de Sigmund Freud. Edição standard brasileira. Rio de Janeiro: Imago, 1976. Vol. XII

'A história do movimento Psicanalítico (1914)' in Obras psicológicas completas de Sigmund Freud. Edição standard brasileira. Rio de Janeiro: Imago, 1976. Vol. XIV

'Algumas reflexões sobre a Psicologia do Escolar (1914)' in Obras psicológicas completas de Sigmund Freud. Edição standard brasileira. Rio de Janeiro: Imago, 1976. Vol. XIII

'Observações sobre o amor transferencial (Novas recomendações sobre a técnica da Psicanálise III (1915)' in Obras psicológicas completas de Sigmund Freud. Edição standard brasileira. Rio de Janeiro: Imago, 1976. Vol. XII

'O mal-estar na civilização (1929)' in Obras psicológicas completas de Sigmund Freud. Edição standard brasileira. Rio de Janeiro: Imago, 1976. Vol. XXI

'Análise terminável e interminável (1937)' in Obras psicológicas completas de Sigmund Freud. Edição standard brasileira. Rio de Janeiro: Imago, 1976. Vol. XXIII

HunEKe, Hans-Werner; STEINIG, Wolfgang. Deutsch als Fremdsprache: eine Einführung. Berlim: Erich Schmidt, 2010.

KUPFER, M. C. M, Freud e a Educação: o mestre do Impossível. São Paulo: Scipione, 1989.

LÜHMANN, Hinrich, ,Schule der Übertragung' in PAZZINI, Karl-Josef / GotTlob, Susanne (Ed.). Einführungen in die Psychoanalyse II: Setting, Traumdeutung, Sublimierung; Angst, Lehren, Norm, Wirksamkeit. Bielefeld: Transcrip, 2006, 97-118.

Maurano, Denise. A Transferência - Psicanálise Passo-a-passo - Vol. 72. Rio de Janeiro: Jorge Zahar, 2004.

MeZAn, Renato, Freud: a Trama dos Conceitos, 6. ed. São Paulo: Perspectiva, 2004.

MRECH, Leny Magalhães, 'Lacan, a educação e o impossível de educar' in Lacan pensa a Educação.II (9), 2008, 18-29.

RochE, Jörg, Fremdsprachenerb, Fremdsprachendidaktik. 2. Auflage. Tübingen: Narr Francke Attempto, 2008.

RoudineSCO, Elisabeth; PlON, Michel, Dicionário de Psicanálise. Rio de Janeiro: Jorge Zahar, 1998.

Stolzmann, Marianne Montenegro; Rickes, Simone Moschen, 'Do dom de transmitir à transmissão de um dom' in Psicanálise e Educação. Revista da Associação Psicanalítica de Porto Alegre. IX (16), 1999, 39-51.

STORCH, Günther, Deutsch als Fremdsprache - Eine Didaktik. Theoretische Grundlagen und praktische Unterrichtsgestaltung. Stuttgart: Wilhelm Fink, 2009.

VOLTOLINI, Rinaldo, 'A relação professor-aluno não existe: corpo e imagem, presença e distância' in ETD - Educação Temática Digital. Campinas, (8), 2007, 119-139.

WiLlemarT, Philippe, 'Psicanálise e pedagogia ou transmissão e formação'. In: Revista USP, São Paulo, Set. I Nov. 1996, 201-209. http://www.usp.br/revistausp/31/17-philippe.pdf $(04 / 08 / 2014)$ 